Boise State University

ScholarWorks

Counselor Education Faculty Publications and

Presentations

Department of Counselor Education

$1-1-2016$

Evaluation of a Brief, School-Based Bullying

Bystander Intervention for Elementary School Students

\author{
Aida Midgett \\ Boise State University \\ Diana Doumas \\ Boise State University \\ Rhiannon Trull \\ Boise State University
}




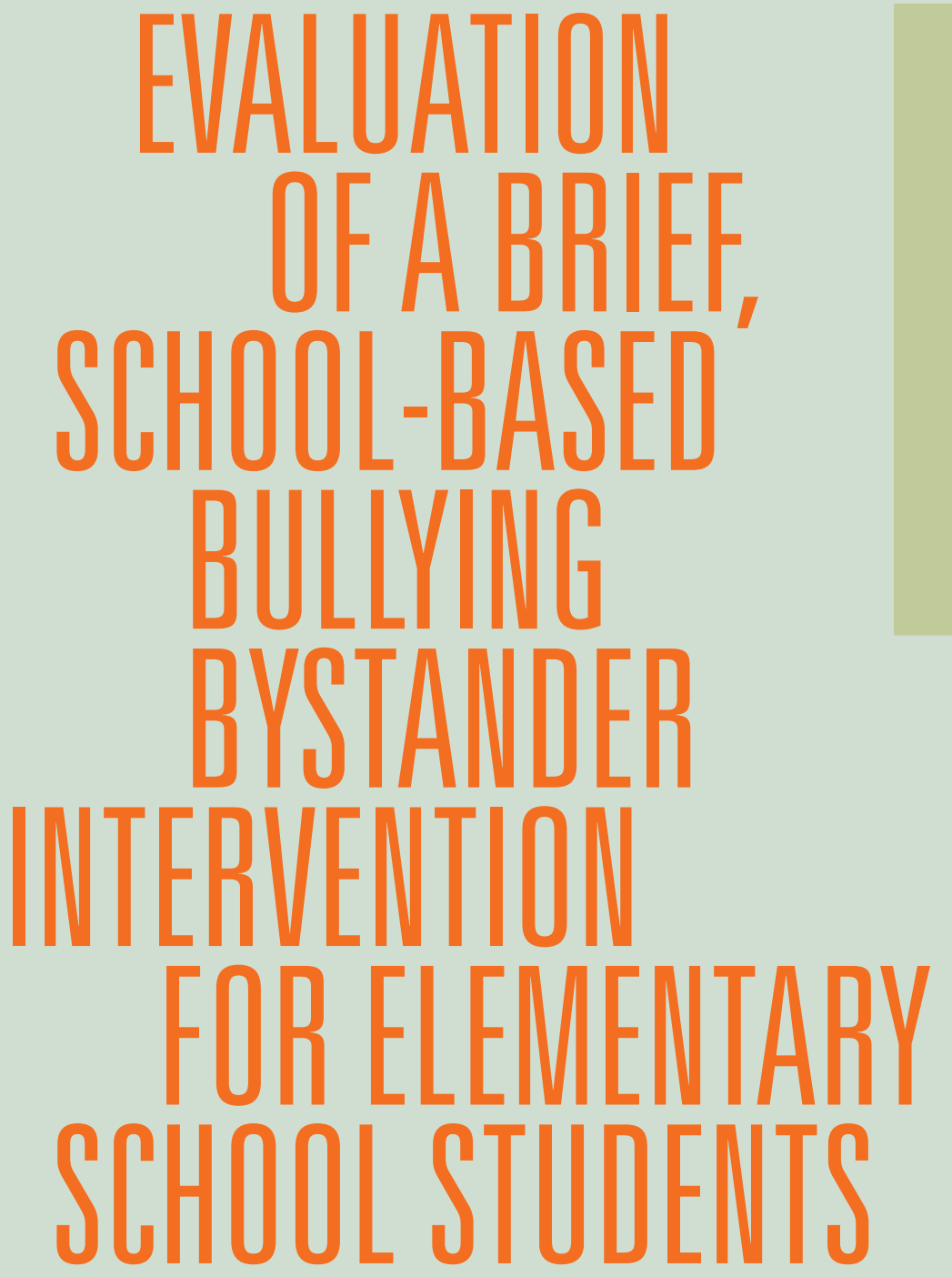

This study evaluated a brief, bystander bullying intervention for elementary school students. Students in the intervention group reported an increase in knowledge and confidence to act as "defenders." Students in the intervention group also reported an increase in self-esteem relative to the control group, although this finding was limited to sixth-grade students. The study found no group differences in sense of school belonging. This article discusses implications for school counselors. ullying is identified as one of the foremost problems faced by youth today (American Educational Research Association, 2013). Although the literature documents consequences for elementary school students who are victims of bullying (Cook, Williams, Guerra, Kim, \& Sadek, 2010; Glew, Fan, Katon, Rivara, \& Kernic, 2005; Kim et al., 2015; Klomek et al., 2009) and who perpetrate bullying behaviors (Cook et al., 2010), negative consequences also are associated with witnessing bullying at school as a bystander (Cook et al., 2010; Demanet \& Van Houtte, 2012; Rivers, Poteat, Noret, \& Ashurt, 2009). Researchers have found that elementary school student bystanders benefit from intervening on behalf of students who are victims of bullying (Olenik-Shemesh, Heiman, \& Eden, 2015). However, research is needed that evaluates the impact of bystander interventions on students trained to intervene as "defenders." This study addresses this gap in research by evaluating the efficacy of a brief, school-based bystander intervention on the socioemotional adjustment of elementary school students trained to act as defenders to intervene in bullying incidences.

\section{Bullying and the Associated} Negative Consequences Bullying is a widespread social problem with approximately $25 \%$ of students in the United States reporting being bullied at school (U.S. Department of Education, 2015; Zhang,

Aida Midgett, Ed.D., is an associate professor and associate chair of Counselor Education at Boise State University in Boise, ID. Email: aidamidgett@boisestate.edu Diana Doumas, Ph.D., is a professor and chair of Counselor Education and Rhiannon Trull is a master's graduate assistant, both at Boise State University.

doi: 10.5330/1096-2409-20.1.172 
Musu-Gillette, \& Oudekerk, 2016). The most prevalent types of bullying students report include: (a) being made fun of, called names, or insulted; (b) being the subject of rumors; (c) being pushed, shoved, tripped, or spit on; (d) being intentionally excluded from activities; (e) being threatened with harm; (f) having peers attempt to make them do things they do not want to do; and $(\mathrm{g})$ having their property intentionally destroyed (U.S. Department of Education, 2015).

Considering the prevalence and types of bullying students report, the wide range of negative consequences linked to bullying is not surprising. Findings from a meta-analysis indicate elementary school students who are victims of bullying report internalizing behaviors such as being withdrawn, depressed, anxious, and avoidant (Cook et al., 2010). Elementary school victimization also is associated with increased suicide attempts and completions in adulthood (Klomek et al., 2009). Further, elementary school students who are victims of bullying report somatization problems including stomachaches and headaches, attention deficit hyperactivity disorder, cognition problems, conduct problems (Kim et al., 2015), and poor academic achievement (Glew et al., 2005). In contrast, elementary students who perpetrate bullying are more likely to engage in externalizing behaviors such as undercontrolled actions characterized by defiant, aggressive, disruptive, and noncompliant behaviors, as well as internalizing behaviors (Cook et al., 2010).

Although much is known regarding socioemotional difficulties associated with bullying for students who are victims or perpetrators, much less is known about consequences for students who witness bullying as bystanders, especially at the elementary school level (Cook et al., 2010). Research conducted with middle school students suggests that when students witness bullying at school they are at greater risk than students directly involved as victims and perpetrators (Rivers et al., 2009). Specifically, Rivers et al. (2009) found that bystanders are at greater risk of substance abuse than students who are bullied and are at higher risk of negative nonclinical outcomes including concerns about schoolwork, drugs and alcohol, body image, and interpersonal and familial problems compared to students who perpetrate bullying behaviors.

\section{Bystander Roles}

Research indicates $60 \%$ of elementary school students report witnessing bullying at school (Aboud \& Miller, 2007). For these students, intervening requires a willingness to engage in risk-taking behavior (Pozzoli \& Gini, 2010). For example, when students intervene on behalf of victims, they also risk being victimized themselves by aggressive peers who view the protective behavior negatively (Meter \& Card, 2015). Thus, students respond differently to bullying incidences when they witness bullying behaviors. four roles, only the defender role is associated with a decrease in bullying behavior. Specifically, researchers have found that when bystanders intervene or defend the target, bullying behavior decreases (Hawkins, Pepler, \& Craig, 2001; Padgett \& Notar, 2013; Salmivalli, 2014; Salmivalli, Voeten, \& Poskiparta, 2011). On the other hand, in elementary school classrooms, when bystanders reinforce students who bully or rarely defend victims, students who are victims report increased social anxiety and peer rejection (Kärnä, Voeten, Poskiparta, \& Salmivalli, 2010). Furthermore, student defenders in elementary school report decreased loneliness and increased social support (Olenik-Shemesh et al., 2015).

\section{Self-Esteem and Sense} of School Belonging

Researchers have identified both selfesteem (Grills \& Ollendick, 2002; Kowalski \& Limber, 2013; Raskaus-

\section{BYSTANDERS ARE AT GREATER RISK OF SUBSTAMCE ABUSE THAN STUDENTS WHO ARE BULLLED AND ARE AT HIGHER BISK OF NEGATIVE NONCLLIICAL OUTCOMES.}

Bystanders are students who witness bullying without being directly involved as a victim or perpetrator and who can have a significant impact on the bullying incident (Padgett $\&$ Notar, 2013). Researchers have also used the term "upstanders" to refer to students who act as defenders on behalf of victims of bullying (Dunn, 2009). Researchers have categorized student bystander responses into four distinct roles: (a) "assistants" who actively and directly help the bully victimize a target, (b) "reinforcers" who laugh at or simply witnesses the situation, (c) "outsiders" who often disengage or walk away from the group, and (d) "defenders" who intervene and/or console the target of bullying (Salmivalli, 2014; Salmivalli, Lagerspetz, Björkqvist, Österman, \& Kaukiainen, 1996, p.15). Of these kas, Rubiano, Offen, \& Wayland, 2015) and sense of school belonging (Duggins, Kuperminc, Henrich, Smalls-Glover, \& Perilla, 2016; Eliot, Cornell, Gregory, \& Fan, 2010; Goldweber, Waasdorp, \& Bradshaw, 2013) as psychological buffers against bullying. Specifically, students with high self-esteem report being targets of bullying less frequently than students with low self-esteem (Kowalski \& Limber, 2013). Further, for students who are victimized, high self-esteem also serves as a buffer against anxiety (Grills \& Ollendick, 2002) and academic problems (Raskauskas et al., 2015). Similarly, a strong sense of school belonging is protective against both victimization (Duggins et al., 2016) and bullying perpetration (Goldweber et al., 2013). Students who have a positive perception of teachers and school 
staff are more willing to seek help for bullying (Eliot et al., 2010). However, students who perpetrate bullying behaviors and who are victims of bullying report decreased sense of school belonging and poor relationships with teachers (Raskauskas, Gregory, Harvey, Rifshara, \& Evans, 2010).
Williford et al., 2012). These studies support the efficacy of comprehensive, school-wide bystander interventions in decreasing anxiety and negative perceptions of peers (Williford et al., 2012) and increasing empathy toward victims and commitment to intervene on behalf of victims (Kärnä et al., 2011).

\section{WHEN BYSTANDERS INTERVENE OR DEEEND THE TARGET, BULLYING BeHAVIOR DECREASES.}

Students who witness bullying report negative consequences (Rivers et al., 2009) and may also become victims themselves (Meter \& Card, 2015) or engage in probullying behaviors (Saarento \& Salmivalli, 2015). Therefore, identifying protective factors for these students is important. Because research indicates elementary school students who act as defenders report increased confidence and a higher sense of support than those who act passively (Olenik-Shemesh et al., 2015), training elementary school bystanders to take on the defender role may increase their self-esteem and sense of belonging, thus buffering them against negative outcomes and future victimization.

\section{Bystander Intervention Programs}

Given the extent of the problem of bullying, all 50 states in the U.S. have legislation that requires school personnel to intervene and protect students against school bullying (U.S. Department of Health and Human Services, 2015). The current standard for schoolbased bullying prevention and intervention is comprehensive, school-wide programs (Ttofi \& Farrington, 2011). According to a meta-analysis, although bystander intervention is an important component of combating school bullying, few programs include this as part of comprehensive interventions (Polanin, Espelage, \& Pigott, 2012). Moreover, only a few studies have examined the impact of bystander interventions on students who are trained to intervene as defenders among elementary school students (Kärnä et al., 2011;
Although some evidence suggests that comprehensive, school-wide programs are associated with positive socioemotional outcomes on bystanders (Kärnä et al., 2011; Williford et al., 2012), these programs place high demands on schools and teachers to deliver instruction (KiVa Antibullying, 2014; Menard \& Grotpeter, 2014; Salmivalli \& Poskiparta, 2012). Thus, comprehensive, school-wide programs can be difficult for many schools to implement. Therefore, a need exists for programs that are practical for schools that lack the resources required to implement a comprehensive school-wide program (Midgett, 2016; Midgett, Doumas, Sears, Lundquist, \& Hausheer, 2015).

\section{The STAC Program}

STAC is a school-based, brief bystander intervention that encourages students to act as defenders on behalf of victims of bullying (Midgett et al., 2015). Bystanders are taught the STAC strategies: "stealing the show," "turning it over," "accompanying others," and "coaching compassion." A unique feature of the STAC program is that it is designed to be implemented by school counselors rather than taught through a teacherdelivered curriculum. Shifting program leadership to school counselors is consistent with the ASCA National Model (American School Counselor Association [ASCA], 2012), which identifies the role of the school counselor as a systemic change agent, promoting student achievement through school-wide initiatives, including programs that promote a safe learning environment.
Thus, an important role for the school counselor is effectively implementing programs that reduce bullying to create a safe school climate and promoting emotional and social skills so students learn acceptable behaviors that improve social interactions (ASCA, 2014). These interactions include creating positive and supportive relationships with one another, demonstrating empathy, and engaging as advocates with the ability to assert themselves when necessary (ASCA, 2014).

Initial research on the STAC program provides support for its effectiveness in teaching student bystanders intervention strategies they can use to act as defenders (Midgett, 2016; Midgett et al., 2015). Specifically, researchers found that after completing the STAC program, middle school students reported an increase in their ability to identify different types of bullying behavior, knowledge of the STAC strategies, and general confidence intervening in bullying situations (Midgett et al., 2015). Researchers also demonstrated preliminary support for the STAC intervention in training elementary school students as defenders, with the greatest effects found among fifth-grade students (Midgett, 2016). Although these studies serve as an important first step in learning about whether STAC is effective in instructing students to intervene as defenders, neither study included a control group or investigated socioemotional outcomes for the students trained to act as defenders.

\section{The Current Study}

Despite evidence that acting as a defender can reduce bullying and is associated with positive adjustment among elementary school student bystanders, to our knowledge, only one study to date (Williford et al., 2012) has investigated the impact of brief, bystander programs on socioemotional outcomes for elementary students trained to act as defenders. Thus, the purpose of this study is to extend the literature by evaluating a brief, bystander intervention on training bystanders to be defenders to increase the socioemotional 
adjustment of these students. More specifically, this study investigated the impact of a brief, bystander intervention, STAC, on increasing reports of knowledge and confidence related to becoming a defender and on increasing self-esteem and sense of school belonging among elementary students trained to act as defenders.

In terms of differences in outcomes by grade level, researchers have found that students in fifth grade differentiate aggressive and prosocial behaviors at a higher level than students in third grade (Sullivan \& Stoner, 2011). Prior research examining the STAC program indicates the training was most effective for fifth-grade students (Midgett, 2016). Therefore, another aim of this study was to examine grade level as a moderator of intervention effects, thereby investigating if one grade level is optimal in terms of bystanders' likelihood to benefit from being trained to act as defenders.

To achieve these aims, the authors randomly assigned students to an intervention group or a wait-list control group. The authors hypothesized that, at a 30-day follow-up, (a) students in the intervention group would report an increase in ability to identify bullying behaviors, knowledge of the STAC strategies, and confidence in intervening in bullying situations compared to those in the control group, (b) students in the intervention group would report an increase in self-esteem measured by the Single-Item SelfEsteem Scale (SISE; Robins, Hendin, \& Trezensiewski, 2001) and sense of school belonging measured by the Psychological Sense of School Membership Scale (PSSM; Goodenow, 1993) compared to students in the control group, and (c) grade level would moderate intervention effects with greater effects demonstrated among students in higher grade levels.

\section{METHODS}

\section{Participants}

Elementary school students from an urban, public Northwestern school participated in this study. The school's population included approximately 458 students (51\% female, $49 \%$ male), with $81 \%$ of students identifying as White, 10\% Hispanic, 5\% Asian American, 2\% African American, and $2 \%$ as two or more races. Of the students at this school, $45 \%$ qualified for free lunch and an additional $8 \%$ qualified for reduced-price lunch. The school is located in a school district in which all elementary schools include kindergarten through sixth grade. The sample of 63 elementary school students included $55.6 \%$ females and $44.4 \%$ males enrolled in fourth $(n=22)$, fifth $(n=20)$, and sixth $(n$ $=21$ ) grades. Participants ranged in age from 9-12 years $(M=10.54$; $S D=0.93)$, with reported racial backgrounds of $71.4 \%$ White, $11.1 \%$ Native American, 3.2\% African American, and $14.3 \%$ other. Overall, $92.1 \%(n=58)$ of the 63 participants completed the 30-day follow-up assessment. The authors found no differences in the rate of attrition across the two groups, $\chi^{2}(1)=1.84, p>.05$. her experiences working with students during classroom lessons, one-on-one brief counseling meetings, and small group meetings. The school counselor selected student leaders to participate because of their potential to act as role models defending victims of bullying at school. After the students were selected, the school counselor briefly met with each student to discuss potential interest in the program. Of the 71 identified students, 67 (94\%) students expressed interest in participating. Interested students received an informed consent form to be signed by a parent or guardian and returned to the school counselor. The school counselor followed up with a phone call to parents or guardians when necessary. Of these 67 parents or guardians, $63(94 \%)$ provided written consent for their child to particpate. The school counselor then met with each of these students briefly to explain the research in more detail and collect student assent. All students with parental or guardian consent assented to participate.

\section{ALtHOUGh BYSTANDER INTERVENTION IS AN IMPORTANT COMPONENT OF COMBATING SCHOOL BULLYING, FEW PROGRAMS INCLUDE THIS.}

\section{Procedure}

The research team for this study consisted of two counselor educators in a program that includes school counseling and a school counseling graduate student. Members of the research team worked with the counselor at the selected school to conduct the study procedures. The school counselor selected 71 students (22-24 per grade level) to participate in the program. In collaboration with teachers, the school counselor selected students perceived by the counselor and teachers as possessing maturity, leadership, and responsibility to pilot the program at her school. To determine leadership potential, the school counselor relied on the teachers' experience with students in the classroom setting and
The participating elementary school students were randomly assigned to the intervention or wait-list control group. Of the 63 eligible students, $50.8 \%(n=32)$ were assigned to the intervention group and $49.2 \%$ $(n=31)$ to the wait-list control group. A series of chi-square and independent sample $t$-test analyses revealed no demographic differences between students in the intervention and wait-list control groups.

All students were given the research questionnaires, which included the Student-Advocates Pre- and PostScale, SISE, PSSM, and demographic questions at baseline (the first week of March) and at a 30-day followup (the first week of April). The first author and research assistants read 


\section{A BRIEF, COUNSELOR-LED BYSTANDER INTERVENTION CAN INCREASE ELEMENTARY SCHOOL STUDENTS' REPORTED KNOWLEDGE AND CONFIDENCE TO ACT APpropriately WHEN thEY OBSERVE BULLYING.}

each item from every questionnaire to the students. After completing the questionnaires at baseline, the intervention group completed a 75 -minute training program during classroom time. Graduate students in a masters in counseling program conducted the training in the school library. Following the training, students in the intervention group participated in a 20-minute small group follow-up meeting by grade level with the first author and a research assistant. After completing the questionnaires at the 30-day follow-up, participants in the wait-list control group completed the 75 -minute training program. The University's Institutional Review Board and the school district approved all study procedures. Additionally, the study followed the American Counseling Association ethical standards (2014).

\section{Instruments}

Student-Advocates Pre- and PostScale. The authors developed the Student-Advocates Pre- and Post-Scale (Midgett et al., 2015) to measure the effectiveness of the STAC training. Specifically, the 11-item self-report questionnaire measures the degree to which the STAC training met the program objectives of increasing student ability to identify bullying behaviors, knowledge of the STAC strategies, and confidence intervening in bullying situations. Examples of items include: "I know what verbal bullying looks like," "I know how to use humor to get attention away from the student being bullied," and "I feel confident in my ability to do something helpful to decrease bullying at my school." Items are rated on a 4-point Likert Scale ranging from I totally disagree to I totally agree. Items are summed to create a total scale score.

The authors established content validity of the questionnaire through professional review of the items. The authors selected three professional reviewers (a school counselor, a school teacher, and a university faculty member with experience in instrument design) to review the questionnaire. The first author generated the items to reflect the content of the training. She then elicited feedback from the three professionals; this included revising language and formatting to be developmentally appropriate for this age group. The three reviewers agreed that the items appeared to measure the three areas described above. The questionnaire has adequate internal consistency for the total scale for elementary and middle school samples, $\alpha=.77-.81$ respectively (Midgett $\&$. Doumas, 2016; Midgett et al., 2015). For this sample, Chronbach's alpha was $\alpha=.75$.

Single-Item Self-Esteem Scale. The research team measured self-esteem using the SISE (Robins et al., 2001). The item, "I see myself as someone who has high self-esteem," is rated on a 5-point Likert Scale ranging from Disagree strongly to Agree strongly. The SISE has moderate test-retest reliability of .75 (Robins et al., 2001), indicating participants have a consistent pattern of responding to the measure over time. The SISE also has established convergent validity, correlating with other psychometrically validated measures of self-esteem, including very high convergent validity (.75 - .80) with the Rosenberg Self-

Esteem scale (RSE; Rosenberg, 1965) and moderate convergent validity $(.52)$ with the Global Self-Esteem Scale of the Self-Perception Profile for Children (Harter, 1985; Robins et al., 2001).
The authors selected the SISE because it adequately measures subjective feelings of self-worth among elementary aged children, providing a practical alternative to longer measures of selfesteem (Robins et al., 2001).

Psychological Sense of School Membership Scale. Sense of school belonging was measured using the PSSM (Goodenow, 1993). The PSSM comprises 18 self-report items that measure students' perception of belonging to their school. Examples include: "People notice when I am good at something," "I am treated with as much respect as other students," and "Teachers here are not interested in people like me." Items are rated on a 5-point Likert Scale ranging from Not at all true to Completely true. Five items were reverse scored with all items summed to create a total scale score. Overall, the PSSM has well-established concurrent and predictive validity and supported factor structures for middle school students (You, Ritchey, Furlong, Shochet, \& Boman, 2011). Students who score high on school belonging measured by the PSSM also report high scores on measures assessing school success (McMahon, Parnes, Keys, \& Viola, 2008), school attendance (Sanchez, Colon, \& Esparza, 2005) and grade point average (Booker, 2007). Researchers also found an inverse relationship between the PSSM and reported depression (Sanchez et al., 2005) and anxiety (McMahon et al., 2008). Researchers have reported test-retest reliablity of .78 for the PSSM over a 4-week period (Hagborg, 1994) and .56 - .60 over a 12 -month period (Shochet, Dadds, Ham, \& Montague, 2006). Reported coefficient alphas range from $.78-.95$ for elementary and middle school samples (You et al., 2011). For this sample, Chronbach's alpha was $\alpha=.85$. Although the PSSM was originally validated with middle school student samples (Goodenow, 1993), the authors selected the PSSM because it is a commonly used measure of school belonging in research with elementary school students (Espelage, Hong, Rao, \& Thornberg, 2015; Gutman \& Midgley, 2000; Im, Hughes, Kwok, 
Puckett, \& Cerdia, 2013; McMahon, Wernsman, \& Rose, 2009; Sari, 2012). Moreover, validation samples include sixth-grade students (Espelage et al., 2015; Gutman \& Midgley, 2000; Im et al., 2013; McMahon et al., 2009; Sari, 2012), which are included as part of the elementary school sample in the current study.

\section{The STAC Intervention}

The first author, a middle school counselor, and two counseling graduate students collaborated to develop the STAC intervention to train students to become "defenders." The authors developed the program in response to a request from a local school counselor whose school did not have the resources to adopt a comprehensive, school-wide intervention. The school counselor was involved in every step of the program development, reviewing the work conducted by the team and providing feedback for program design and implementation. The STAC program includes both didactic and role-playing components and is adapted from CARES, which is the bystander component of Bully-Proofing, a comprehensive school-wide intervention (Garrity, Jens, Porter, Sager, \& Short-Camilli, 2004). The program was developed initially as a 90-minute training for middle school students and was adapted to 75 minutes for elementary school students. To adapt the program to the elementary school level, the researchers shortened the didactic component and consulted with an elementary school counselor who reviewed the program and helped modify the role plays so scenarios would be appropriate for this age group. Graduate students provided the STAC program. The intervention is a training session that includes a didactic component and an experiential role-playing component that are used to train the students in the four STAC Strategies (for details, see Midgett et al., 2015). Following the training, the first and third authors conducted two 20-minute group meetings over the next 30 days. The program delivery (including the didactic and role-play- ing components), modified intervention strategies, and shift from classroom teachers to school counselors as leaders in implementation are features that distinguish the STAC program from CARES (Garrity et al., 2004).

Didactic Component. The didactic component included ice-breaker exercises, an audiovisual presentation, and hands-on activities to engage elementary school students in the learning process. Trainers conducted an audiovisual presentation teaching students about (a) different types of bullying; (b) characteristics of students who bully, including the likelihood they have been bullied themselves, to foster empathy and separate the behavior from the student; (c) negative associated consequences of bullying for students who are victims, perpetrators of bullying, and bystanders; (d) bystander roles and the importance of acting as a defender, and (e) the STAC strategies used for intervening in bullying situations. using the strategies. Students practiced all four STAC strategies and trainers made an effort to include all students in at least one role play. After the small groups conducted all role plays, each group demonstrated one role play to the larger group. Trainers fostered a supportive environment where all students clapped and cheered for each other after each demonstration.

Training Conclusion. The training concluded with the small groups coming together and each student sharing his or her favorite STAC strategy, signing a petition stating "bullying stops with me," and receiving a certificate of participation.

\section{The STAC Strategies.}

"Stealing the Show." Stealing the show involves using humor to turn students' attention away from the bullying situation. Trainers teach defenders to use their sense of humor when they observe bullying to displace the atten-

\section{SIXTH GRADE MAY BE AN OPTIMAL TIME TO IMPLEMENT THE STAC PROGRAM TO PROVIDE A PROTECTIVE EFFECT AgAIIST NEGATIUE CONSEQUENCES FOR BYSTANDERS.}

Role Plays. Trainers divided students into small groups by grade level and practiced utilizing the STAC strategies through four set role plays. Role plays included hypothetical bullying situations that students might encounter in elementary school. Examples include, "In the bus on the way home from school, students begin to make fun of Carly. They begin to poke her with their fingers and their pencils. They also flick the top of her head. You are sitting nearby and see this," and "At recess, some of the boys you are friends with begin to make fun of Cameron. They repeat back words he says in a mocking way to put him down. They want to make Cameron feel bad. You see all of this happening." Trainers asked students which STAC strategies they could utilize and helped them set up skits to practice tion away from the target. Trainers provided examples such as defenders telling a funny joke or pretending to trip by acting silly.

"Turning it Over." Turning it over involves informing an adult about the situation and asking for help. During the training, students identified safe adults at school who can help. Students were taught to always turn it over if there is physical bullying taking place, or if they are unsure how to intervene.

“Accompanying Others.” Accompanying others involves the defender reaching out to the student who was targeted to communicate that what happened is not acceptable, that the student who was targeted is not alone at school, and that the defender cares about them. Trainers taught this to students by providing examples of how they can use this strategy such as approaching a peer 
Grade Level

\begin{tabular}{|c|c|c|c|c|c|}
\hline & & $\begin{array}{l}\text { Fourth } \\
(n=20)\end{array}$ & $\begin{array}{c}\text { Fifth } \\
(n=20)\end{array}$ & $\begin{array}{c}\text { Sixth } \\
(n=18)\end{array}$ & $\begin{array}{c}\text { Total } \\
(N=58)\end{array}$ \\
\hline & Outcomes & $M(S D)$ & $M(S D)$ & $M(S D)$ & $M(S D)$ \\
\hline \multicolumn{6}{|l|}{ Peer Advocacy } \\
\hline \multirow[t]{2}{*}{ Control } & Baseline & $36.27(4.90)$ & $37.11(4.29)$ & $39.70(2.87)$ & $37.67(4.26)$ \\
\hline & Follow-up & $35.73(4.90)$ & $37.78(4.94)$ & $37.80(4.39)$ & $37.03(4.69)$ \\
\hline \multirow[t]{2}{*}{ Intervention } & Baseline & $35.44(6.48)$ & $34.90(3.84)$ & $39.25(3.11)$ & $36.37(4.93)$ \\
\hline & Follow-up & $37.89(4.70)$ & $40.00(3.43)$ & $41.25(2.55)$ & $39.67(3.81)$ \\
\hline \multicolumn{6}{|l|}{ Self-Esteem } \\
\hline \multirow[t]{2}{*}{ Control } & Baseline & $5.09(1.45)$ & $5.78(1.99)$ & $5.60(1.35)$ & $5.47(1.57)$ \\
\hline & Follow-up & $5.09(2.02)$ & $5.56(1.88)$ & $5.10(1.52)$ & $5.23(1.77)$ \\
\hline \multirow[t]{2}{*}{ Intervention } & Baseline & $5.78(0.97)$ & $5.91(1.04)$ & $5.50(1.60)$ & $5.75(1.18)$ \\
\hline & Follow-up & $5.22(1.56)$ & $5.36(1.50)$ & $6.13(1.46)$ & $5.54(1.50)$ \\
\hline
\end{tabular}

Sense of Belonging

\begin{tabular}{|c|c|c|c|}
\hline \multirow[t]{2}{*}{ Control } & Baseline & $73.55(5.24)$ & $70.44(10$ \\
\hline & Follow-up & $71.52(9.95)$ & $69.11(13$ \\
\hline \multirow[t]{2}{*}{ Intervention } & Baseline & $78.22(6.85)$ & $71.36(10$ \\
\hline & Follow-up & 78.44 (7.04) & $73.09(12$ \\
\hline
\end{tabular}

after they were targeted and inviting them to go for a walk during recess.

"Coaching Compassion." Coaching compassion involves gently confronting the bully either during or after the bullying incident to communicate that his or her behavior is unacceptable. The defender also encourages the student who bullied to consider what it would feel like to be the target in the situation, thereby fostering empathy toward the target. Defenders were encouraged to implement coaching compassion when they have a relationship with the student who bullied or if the student who bullied is in a younger grade and the defender believes the younger student will respect them.

Post-Training Groups. Students who participated in the STAC training met with the first author and a research assistant, a master's student in school counseling, for two 20-minute group meetings per grade level after the training was conducted. During these meetings, the researchers helped students recall the STAC strategies and discussed with students which strategies they had utilized and whether they seemed to be effective in stopping bullying. The researchers also answered any questions from students related to being a defender and helped them brainstorm effective ways to implement the strategies, use more than one strategy to intervene, and, when appropriate, to work as a team to intervene during or after a bullying incident.

\section{DATA ANALYSIS}

The authors used SPSS version 21.0 to conduct all analyses. They con- ducted three GLM repeated measures analyses of variance (ANOVAs) to examine differences, from baseline to follow-up assessments, in knowledge and confidence to act as a defender, self-esteem, and sense of belonging. The three independent variables were time (baseline, follow-up), group (intervention, control), and grade (fourth, fifth, sixth). The authors included grade level as an independent variable to examine grade as a moderator of intervention effects. They used an alpha level of $p<.05$ to determine statistical significance and used partial eta squared $\left(\eta_{p}^{2}\right)$ as the measure of effect size.

\section{RESULTS}

The authors examined data for extreme case and for normality and did not identify any outliers. All variables were within the normal range for skew and kurtosis. Means and standard deviations by group and grade level for each outcome variable are presented in Table 1. 


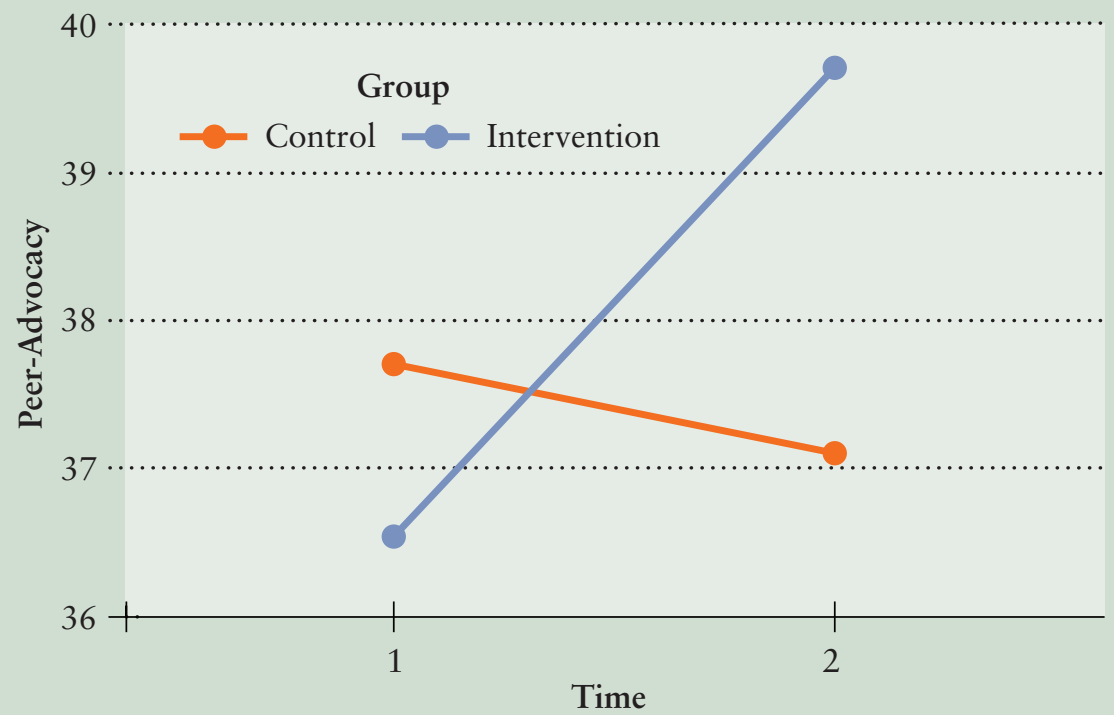

\section{FIGURE 2 BASELINE AND FOLLOW-UP SELF-ESTEEMI} BY GROUP FOR SIXTH GRADE STUDENTS

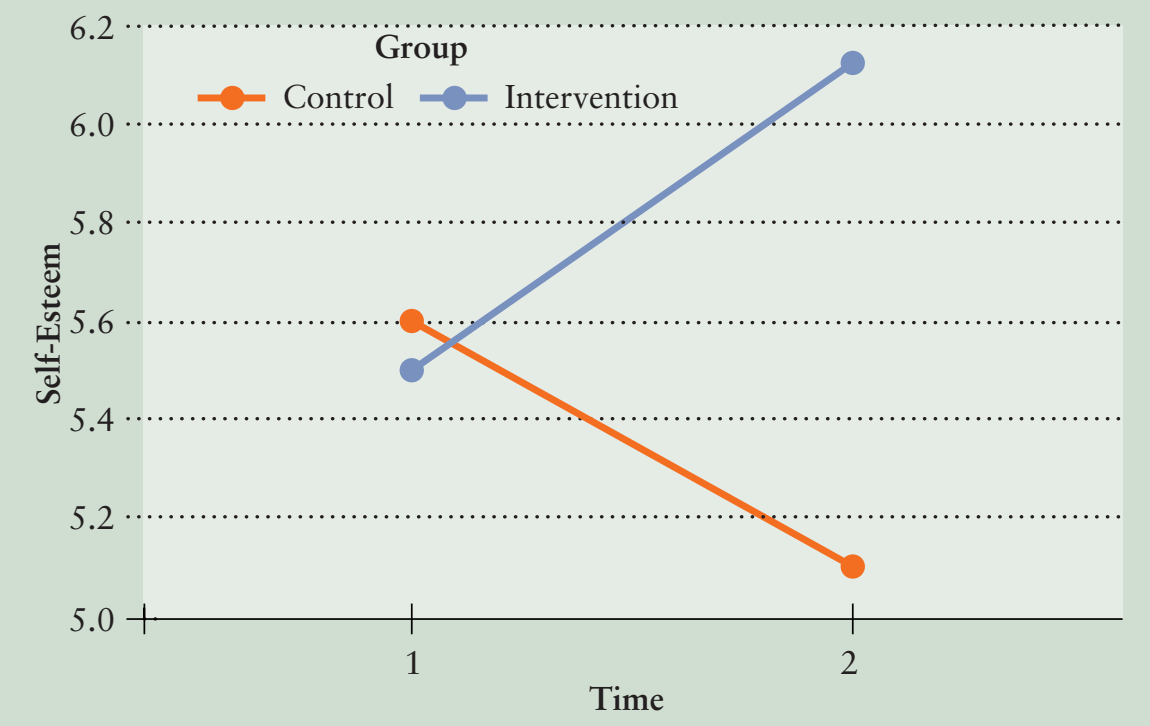

\section{Knowledge and Confidence} to Act as a Defender

Results indicated a significant main effect for time, Wilks' Lambda $=.88$, $F(1,52)=6.74, p<.01, \eta^{2}{ }_{p}=.12$, and significant interaction effect for Time x Group, Wilks' Lambda $=.78, F(1$, $52)=14.34, p<.001, \eta_{p}^{2}=.22 . \mathrm{Ex}-$ amination of the $\eta_{p}^{2}$ indicates the effect size was large. No other interaction effects were significant. As hypothesized, students in the intervention group reported an increase in knowledge of bullying and the STAC strategies, and in their confidence to act as a defender relative to students in the wait-list control group (see Figure 1).

\section{Self-Esteem}

Results indicated a significant interaction effect for Time x Group x Grade, Wilks' Lambda $=.89, F(1,52)=3.37$, $p<.05, \eta_{p}^{2}=.12$. Examination of the $\eta_{p}^{2}$ indicates the effect size was medi- um. No other main effects or interaction effects were significant. Follow-up analyses indicated a significant Time $\mathrm{x}$ Group interaction for sixth-grade students only, Wilks' Lambda $=.78$, $F(1,16)=4.42, p<.05, \eta_{p}^{2}=.22$. The interaction effect was not significant for fourth-grade students, Wilks' Lambda $=.89, F(1,18)=2.25$, $p>.05, \eta_{p}^{2}=.11$, or fifth-grade students, Wilks' Lambda $=.98, F(1$, 18) $=2.00, p>.05, \eta_{p}^{2}=.02$. The $\eta_{p}^{2}$ indicates the effect size was large. As seen in Figure 2, sixth-grade students in the intervention group reported an increase in self-esteem, whereas students in the wait-list control group reported a decrease in self-esteem.

\section{Sense of School Belonging}

Results indicated no significant main effects or interaction effects for sense of belonging. Contrary to the hypothesis, the authors found no significant differences between the intervention group and wait-list control group.

\section{DISCUSSION}

Because bullying begins to escalate in late elementary school (Pellegrini \& Van Ryzin, 2011), identifying effective bullying programs that can be implemented at the elementary school level is important. Overall, results provided support for the STAC program as a promising approach for equipping elementary school students who witness bullying with the knowledge and confidence they need to act as "defenders." Results also provided partial support for the impact of the STAC program on socioemotional adjustment outcomes for students. Specifically, sixth-grade students trained to act as defenders in the STAC program reported a larger increase in selfesteem relative to those in the wait-list control group. There were, however, no significant differences between the two groups in sense of belonging.

As hypothesized, students participating in the STAC program reported a significant increase in knowledge of what different types of bullying look 
like, knowledge of the STAC strategies, and general confidence intervening in bullying situations compared to students in the wait-list control group. These results extend prior research demonstrating differences among students completing the STAC program (Midgett, 2016; Midgett et al., 2015) by demonstrating these effects using random assignment to experimental condition (intervention vs. control group). Thus, findings indicate that a brief, counselor-led bystander intervention can increase elementary school students' reported knowledge and confidence to act appropriately when they observe bullying, rather than participating in the bullying either actively or through passive avoidance. However, in contrast to prior research indicating the STAC training is most effective for fifth-grade students (Midgett, 2016), grade level did not moderate these effects. Whether the discrepancy between these two studies is related to differences in the samples or differences in the research methodology (e.g., pre-post design vs. random assignment to experimental condition) is not clear. for sixth-grade students only. Thus, participating in the STAC training may provide a buffering effect for sixthgrade students who observe bullying. This finding is consistent with prior research indicating that the training is more effective for older students (Midgett, 2016) and that students in upper elementary school are primed to be trained as defenders (Sullivan \& Stoner, 2011). Taken together, these findings suggest that sixth grade may be an optimal time to implement the STAC program to provide a protective effect against negative consequences for bystanders. However, although the SISE has moderate convergent validity among elementary school students, correlations between the SISE and established measures of self-esteem are higher for older students (Robins et al., 2001). Thus, one explanation for changes in self-esteem among sixthgrade students only is that the measure may be more valid for sixth-grade students relative to those in lower grades.

Finally, the authors found no significant differences between the two groups on sense of school belonging. Students invited to participate in the

\section{THE STAC PROGRAM WAS DESIGNED FOR SCHOOL COUNSELORS TO TAKE ON A LEADERSHIP ROLE IN PROGRAM IMPLEMENTATION, WHICH IS IN LINE WITH THE ASCA NATIONAL MODEL.}

In contrast, results only partially supported hypotheses regarding socioemotional adjustment. As predicted, students in the intervention group reported a larger increase in self-esteem compared to students in the wait-list control group. This is an important finding considering increased selfesteem can serve as a buffer against the negative effects associated with bullying (Grills \& Ollendick, 2002; Kowalski \& Limber, 2013; Raskauskas et al., 2015). However, this effect was moderated by grade level. Specifically, the difference in self-esteem between the two groups was significant study were selected because school personnel perceived them to be leaders at school with the potential to positively impact their peers. Therefore, it is possible that the results of sense of belonging were not significant because the students trained to act as defenders already felt like a meaningful part of their school. This explanation is supported by examination of the sense of belonging scores, which were already high at baseline. Thus, because sense of belonging can protect students against victimization (Duggins et al., 2016) and is associated with decreased bullying perpetration
(Goldweber et al., 2013), it would be interesting to investigate if sense of belonging increased when training students who are not identified as leaders. An alternative explanation for the lack of significant findings for sense of belonging may be related to the choice of measure. Although the PSSB has been used with elementary school students (Espelage et al., 2015; Gutman \& Midgley, 2000; Im et al., 2013; Sari, 2012), its validity has not been established with this age group.

\section{Limitations}

Although this study extends the literature investigating brief, bystander intervention programs, readers should consider certain limitations. First, a relatively small sample size and largely White sample limit the generalizability of the results. Participants were not randomly selected; instead, the school counselor, in collaboration with teachers, invited students to be trained based on perceptions of students as leaders. The researchers did not utilize an objective measure to define inclusion and exclusion criteria. Thus, selection procedures also limit the generalizability of the study results. Next, information was obtained through self-report questionnaires, potentially leading to biased or distorted reporting, especially at the elementary school level. However, children are able to provide useful information about their experience when asked Likert-type questions in a manner that is meaningful to them (Christensen \& James, 2008). Therefore, the researchers read the surveys to students in an effort to increase the quality of the data. Another limitation regarding measurement is the selection of the SISE and PSSB, both of which may be more valid measures for students in middle school (including sixth grade), as noted. Finally, although the current study represents an important step in evaluating a brief, bystander program with elementary school students, the researchers did not examine whether students trained to intervene as defenders utilized the STAC strategies, the mechanisms through which 
being trained as a defender increases self-esteem for students in upper grade levels, or the impact of the STAC program on the prevalence of bullying at school.

\section{Directions for Future Research}

This study serves as a first step in evaluating the STAC program, but future research is needed to establish the efficacy of the program with elementary school students. Researches need to include larger and more diverse student samples to increase the generalizability of the results. It is also important to use random selection procedure for recruitment of participants. Further, investigating the effects of the program after training all students at school to act as defenders would be interesting, instead of only selecting leaders to be trained. Another important investigation would be whether students trained in the program utilize the STAC strategies they learn in the training. Measurement of the program's impact on decreasing bullying also is essential in establishing the efficacy of the STAC program. Researchers can evaluate the efficacy of the STAC program by evaluating school outcome data, including reports of bullying at school from students, teachers, and staff.

\section{Implications for School Counselors}

This study has practical implications for school counselors. Although comprehensive, school-wide intervention programs are considered a best practice for bullying intervention, these programs can be difficult to implement due to required resources and time allocation. Thus, research investigating brief, cost-effective programs is needed. Results from this study suggest that the STAC program, which shifts implementation from teachers to school counselors and requires few resources for implementation, may be a promising approach to bullying intervention. Although more research is needed to evaluate the efficacy of the program in decreasing bullying behavior, results of this study provide initial support for a counselor-led pro- gram that can train students to act as defenders to reduce bullying behavior.

Results from this study provide preliminary evidence suggesting the STAC program can increase self-esteem for older elementary school students trained to act as defenders to stop bullying at school. This is an important finding because high self-esteem buffers students against bullying (Grills \& Ollendick, 2002; Kowalski \& Limber, 2013; Raskauskas et al., 2015) and students who intervene on behalf of victims can become a target of bullying themselves (Meter \& Card, 2015). This is particularly important because bullying begins to escalate in upper elementary school as students prepare to transition to middle school (Pellegrini \& Van Ryzin, 2011). School counselors can utilize the STAC program to increase protective factors against bullying for older students by expanding program implementation to all sixth grade students. Further, the STAC program was designed for school counselors to take on a leadership role in program implementation, which is in line with the ASCA National Model's (2012) identification of school counselors as systemic change agents implementing programs promoting a safe learning environment and teaching students appropriate social and emotional skills (ASCA, 2014).

Finally, school counselors can adapt the STAC program to meet the needs of their school and incorporate the training into their classroom lesson curriculum. This is consistent with the ASCA National Model's (2012; 2014) identification of the importance of the school counselor role in delivery of a school counseling core curriculum designed for students' developmentally appropriate knowledge, attitudes, and skills. School counselors can also conduct follow-up meetings within the context of school counseling program lessons where they discuss the strategies and implementation of using the STAC program to combat bullying at school and to potentially increase student self-esteem. For schools with limited counseling resources, school counselors can work in partnership with a local counselor education program to provide STAC training with the help of counseling students.

\section{CONCLUSION}

This study evaluated a brief, schoolbased bystander bullying intervention for elementary school students. Results indicated that students who completed the STAC intervention reported increased knowledge of different types of bullying behavior, knowledge of the STAC strategies, and general confidence intervening as a "defender." Findings also show partial support that training students to act as defenders may increase socioemotional protective factors against bullying for older students. Overall, results suggest the STAC intervention is a promising counselor-led approach to bystander bullying intervention that can be implemented with significantly fewer resources than comprehensive schoolwide programs.

\section{REFERENCES}

Aboud, F., \& Miller, L. (2007). Promoting peer intervention in name-calling. South African Journal of Psychology, 37(4), 803-819.

American Counseling Association. (2014). 2014 ACA code of ethics. Alexandria, VA: Author.

American Educational Research Association. (2013). Prevention of bullying in schools, colleges, and universities: Research report and recommendations. Washington, DC: Author.

American School Counselor Association. (2012). ASCA National Model: A framework for school counseling programs (3rd ed.). Alexandria, VA: Author.

American School Counselor Association. (2014). ASCA mindsets and behaviors for student success: $K-12$ college- and career-readiness standards for every student. Alexandria, VA: Author.

Booker, K. C. (2007). Likeness, comfort, and tolerance: Examining African American adolescents' sense of school belonging. The Urban Review, 39, 301-317. doi:10.1007/s11256-007-0053-y 
Christensen, P., \& James, A. (2008). Research with children: Perspectives and practices (2nd ed.). London, UK: Routledge.

Cook, C., Williams, K. R., Guerra, N. G., Kim, T. E., \& Sadek, S. (2010). Predictors of bullying and victimization in childhood and adolescence: A metaanalytic investigation. School Psychology Quarterly, 25, 65-83. doi:10.1037/a0020149

Demanet, J., \& Van Houtte, M. (2012). The impact of bullying and victimization on students' relationships. American Journal of Health Education, 43, 104-113. doi:10.1080/19325037.2012.10599225

Duggins, S. D., Kuperminc, G. P., Henrich, C. C., Smalls-Glover, C., \& Perilla, J. L. (2016). Aggression among adolescent victims of school bullying: Protective roles of family and school connectedness. Psychology of Violence, 6, 205-212. doi:10.1037/a0039439

Dunn, S. T. M. (2009). Upstanders: Student experiences of intervening to stop bullying (Doctoral dissertation). Retrieved from ProQuest Dissertations \&Theses Global. (NR55337)

Eliot, M., Cornell, D., Gregory, A., \& Fan, X. (2010). Supportive school climate and student willingness to seek help for bullying and threats of violence. Journal of School Psychology, 48, 533-553.

Espelage, D. L., Hong, J. S., Rao, M. A., \& Thornberg, R. (2015). Understanding ecological factors associated with bullying across the elementary to middle school transition in the United States. Violence and Victims, 30(3), 470-487. doi:10.1891/0886-6708.VV-D-14-00046

Garrity, C., Jens, K., Porter, W., Sager, N., \& Short-Camilli, C. (2004). Bullyproofing your school: Working with victims and bullies in elementary schools (3rd ed.). Longmont, CO: Sopris West.

Glew, G. M., Fan, M.Y., Katon, W., Rivara, F. P., \& Kernic, M. A. (2005). Bullying, psychosocial adjustment, and academic performance in elementary school. Archives of Pediatrics and Adolescent Medicine, 159(11), 1026-1031. doi:10.1001/archpedi.159.11.1026

Goldweber, A., Waasdorp,T. E., \& Bradshaw, C. P. (2013). Examining the link between forms of bullying behaviors and perceptions of safety and belonging among secondary school students. Journal of School Psychology, 51, 469-485. doi:10.1016/j.jsp.2013.04.004
Goodenow, C. (1993). The psychological sense of school membership among adolescents: Scale development and educational correlates. Psychology in the Schools, 30, 79-90. doi:10.1002/1520-6807 (199301)30:1<79::AID-

PITS2310300113>3.0.CO;2-X

Grills, A. E., \& Ollendick, T. H. (2002). Peer victimization, global self-worth, and anxiety in middle school children. Journal of Clinical Child \& Adolescent Psychology, 31, 59-68.

Gutman, L. M., \& Midgley, C. (2000). The role of protective factors in supporting the academic achievement of poor African American students during the middle school transition. Journal of Youth and Adolescence, 29(2), 223-248.

Hagborg, W. J. (1994). An exploration of school membership among middleand high-school students. Journal of Psychoeducational Assessment, 12, 312-323.

Harter, S. (1985) Manual for the Selfperception Profile for Children. Denver, CO: University of Denver.

Hawkins, D. L., Pepler, D. J., \& Craig, W. M. (2001). Naturalistic observations of peer interventions in bullying. Social Development, 10, 512-527. doi:10.1111/1467-9507.00178

Im, M. H., Hughes, J. H., Kwok, O., Puckett, S., \& Cerdia, C. A. (2013). Effect of retention in elementary grades on transition to middle school. Journal of School Psychology, 51(3), 349-365. doi:10.1016/j.jsp.2013.01.004

Kärnä, A., Voeten, M., Little, T. D., Poskiparta, E., Alanen, E., Salmivalli, C. \& Ka, A. (2011). Going to scale: A non-randomized nationwide trial of the $\mathrm{KiVa}$ anti-bullying program for grades 1-9. Journal of Consulting and Clinical Psychology, 79, 796-805.

Kärnä, A., Voeten, M., Poskiparta, E., \& Salmivalli, C. (2010). Bystanders' behaviors moderate the effects of risk factors on victimization. Merrill-Palmer Quarterly, 56(3), 261-282.

Kim, J. W., Lee, K. S., Lee, Y. S., Han, D. H., Min, K. J., Song, S. H., ... Kim, J. O. (2015). Factors associated with group bullying and psychopathology in elementary school students using child-welfare facilities. Journal of Neuropsychiatric Disease and Treatment, 11, 991-998. doi:10.2147/NDT.S76105

KiVa Antibullying. (2014). Frequently asked questions. Retrieved from http:// www.kivaprogram.net/faq
Klomek, A. B., Sourander, A., Niemela, S., Kumpulainen, K., Piha, J., Tamminen, T., ... Gould, M. S. (2009). Childhood bullying behaviors as a risk for suicide attempts and completed suicides: $A$ population-based birth cohort study. Journal of the American Academy of Child and Adolescent Psychiatry, 48(3), 254-261. doi:10.1097/chi.0b013e318196b91f

Kowalski, R. M., \& Limber, S. P. (2013). Psychological, physical, and academic correlates of cyberbullying and traditional bullying. Journal of Adolescent Health, 53, S13-S20.

McMahon, S. D., Parnes, A. L., Keys, C. B., \& Viola, J. J. (2008). School belonging among low-income urban youth with disabilities: Testing a theoretical model. Psychology in the Schools, 45, 387-401. doi:10.1002/pits.20304

McMahon, S. D., Wernsman, J., \& Rose, D. S. (2009). The relation of classroom environment and school belonging to academic self-efficacy among urban fourth- and fifth-grade students. The Elementary School Journal, 109(3), 267-281.

Menard, S., \& Grotpeter, J. K. (2014). Evaluation of bully-proofing your school as an elementary school antibullying intervention. Journal of School Violence, 13(2), 188-209. doi:10.1080/15388220.2013.840641

Meter, D. J., \& Card, N. A. (2015). Defenders of victims of peer aggression: Interdependence theory and an exploration of individual, interpersonal, and contextual effects on the defender participant role.

Developmental Review, 38, 222-240.

Midgett, A. (2016). Bullying: How counselors can intervene. Counseling Today, 58(12), 39-43.

Midgett, A., \& Doumas, D. M. (2016). Training elementary school students to intervene as peer-advocates to stop bullying at school: A pilot study. Journal of Creativity and Mental Health, 11, 353-365. doi:10.1080/15401383.2016.1164645

Midgett, A., Doumas, D., Sears, D. Lundquist, A., \& Hausheer, R. (2015). A bystander bullying psychoeducation program with middle school students: A preliminary report. The Professional Counselor, 5, 586-500. doi:10.15241/am.5.4.486

Olenik-Shemesh, D., Heiman, T., \& Eden, S. (2015). Bystanders' behavior in cyberbullying episodes: Active and passive patterns in the context of personal-socio-emotional factors. Journal of Interpersonal Violence, 1-26. doi:10.1177/0886260515585531 
Padgett, S., \& Notar, C. E. (2013). Bystanders are the key to stopping bullying. Universal Journal of Educational Research, 1(2), 33-41. doi:10.13189/ujer.2013.010201

Pellegrini, A. D., \& Van Ryzin, M. J. (2011). Part of the problem and part of the solution: The role of peers in bullying, dominance, and victimization during the transition from primary to secondary school. In D. L. Espelage \& S. M. Swearer (Eds.), Bullying in North American schools (pp. 91-99). New York, NY: Routledge.

Polanin, J. R., Espelage, D. L., \& Pigott, T. D. (2012). A meta-analysis of schoolbased bullying prevention programs' effects on bystander intervention behavior. School Psychology Review, 41, 47-65.

Pozzoli, T., \& Gini, G. (2010). Active defending and passive bystanding behavior in bullying: The role of personal characteristics and perceived peer pressure. Journal of Abnormal Child Psychology, 38, 815-827. doi:10.1007/s10802-010-9399-9

Raskauskas, J. L., Gregory, J., Harvey, S. T., Rifshana, F., \& Evans, I. M. (2010). Bullying among primary school children in New Zealand: Relationships with prosocial behaviour and classroom climate. Educational Research, 52, 1-13. doi:10.1080/00131881003588097

Raskauskas, J. L., Rubiano, S., Offen, I., \& Wayland, A. K. (2015). Do social self-efficacy and self-esteem moderate the relationship between peer victimization and academic performance? Social Psychology of Education, 18, 297-314. doi:10.1007/s11218-015-9292-z

Rivers, I., Poteat, V. P., Noret, N., \& Ashurst, N. (2009). Observing bullying at school:The mental health implications of witness status. School Psychology Quarterly, 24, 211-223. doi:10.1037/a0018164

Robins, R. W., Hendin, H. M., \& Trzesniewski, K. H. (2001). Measuring global self-esteem: Construct validation of a single-item measure and the Rosenberg Self-Esteem Scale. Personality and Social Psychology Bulletin, 27, 151-161.

Rosenberg, M. (1965). Society and the adolescent self-image. Princeton, $\mathrm{NJ}$ : University Press.
Saarento, S., \& Salmivalli, C. (2015). The role of classroom peer ecology and bystanders' responses in bullying. Child Development Perspectives, 9 201-205. doi:10.1111/cdep.12140

Salmivalli, C. (2014). Participant roles in bullying: How can peer bystanders be utilized in interventions? Theory into Practice, 53(4), 286-292. doi:10.1080/00405841.2014.947222

Salmivalli, C., Lagerspet, K., Björkqvist, K., Österman, K., \& Kaukiainen, A. (1996). Bullying as a group process: Participant roles and their relations to social status within the group. Aggressive Behavior, 22, 1-15. doi:10.1002/(SICI) 1098-2337 (1996)22:13.0.CO;2-T

Salmivalli, C., \& Poskiparta, E. (2012). Making bullying prevention a priority in Finnish schools: the KiVa antibullying program. New Directions for Youth Development, 133, 41-53.

Salmivalli, C., Voeten, M., \& Poskiparta, E. (2011). Bystanders matter: Associations between reinforcing, defending, and the frequency of bullying behavior in classrooms. Journal of Clinical Child \& Adolescent Psychology, 40, 668-676. doi:10.1080/15374416.2011.597090

Sanchez, B., Colon, Y., \& Esparza, P. (2005). The role of sense of school belonging and gender in the academic adjustment of Latino adolescents. Journal of Youth and Adolescence, 34, 619-628. doi:10.1007/s10964-005-8950-4

Sari, M. (2012). Sense of school belonging among elementary school students. Cukurova University Faculty of Education Journal, 41(1), 1-11.

Shochet, I. M., Dadds, M. R., Ham, D., \& Montague, R. (2006). School connectedness is an underemphasized parameter in adolescent mental health: Results of a community prediction study. Journal of Child and Adolescent Psychology, 35, 170-179. doi:10.1207/s15374424jccp3502_1

Sullivan, R. B., \& Stoner, G. (2011). Developmental and gender differences in elementary school children's recognition of bullying. Pastoral Care in Education: An International Journal of Personal, Social, and Emotional Development, 30, 113-125.
Ttofi, M. M., \& Farrington, D. P. (2011). Effectiveness of school-based programs to reduce bullying: A systematic and meta-analytic review. Journal of Experimental Criminology, 7, 27-56. doi:10.1007/s11292-010-9109-1

U.S. Department of Education, National Center for Education Statistics. (2016). Indicators of school crime and safety: 2014 (NCES 2015-072). Retrieved from https://nces.ed.gov/fastfacts/display. asp id $=719$

U.S. Department of Health and Human Services. (2015). StopBullying.gov. (n.d.). Retrieved from http://www. stopbullying.gov/

Williford, A., Boulton, A., Noland, B., Little, T. D., Kärnä, A. \& Salmivalli, C. (2012). Effects of the KiVa anti-bullying program on adolescents' depression, anxiety and perception of peers. Journal of Abnormal Child Psychology, 40, 289-300.

You, S., Ritchey, K. M., Furlong, M. J., Shochet, I., \& Boman, P. (2011). Examination of the latent structure of the psychological sense of school membership scale. Journal of Psychoeducational Assessment, 29, 225-237. doi:10.1177/0734282910379968

Zhang, A., Musu-Gillette, L., \& Oudekerk, B. A. (2016). Indicators of school crime and safety: 2015 (NCES 2016-079/NCJ 249758). Washington, DC: National Center for Education Statistics, U.S. Department of Education, and Bureau of Justice Statistics, Office of Justice Programs, U.S. Department of Justice.

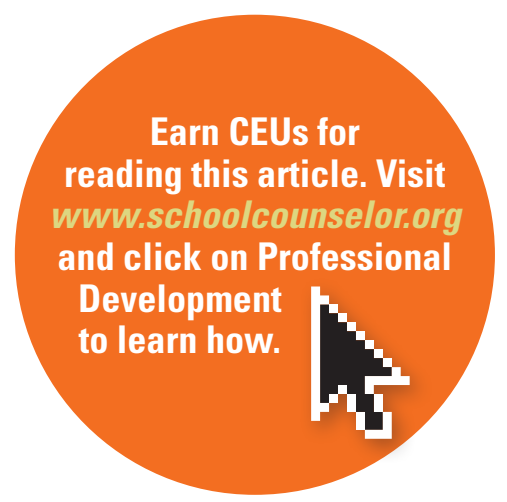

